\title{
Is this person with dementia (currently) competent to request euthanasia? A complicated and underexplored question
}

\author{
Scott YH Kim ๑ , Dominic Mangino, ${ }^{1}$ Marie Nicolini ${ }^{1,2}$
}

'Department of Bioethics, National Institutes of Health, Bethesda, Maryland, USA ${ }^{2}$ Interfaculty Center for Biomedical Ethics and Law, KHLeuven, Leuven, Belgium

\section{Correspondence to}

Dr Scott YH Kim, Department of Bioethics, National Institutes of Health, Bethesda, MD 20892, USA; scott.kim@nih.gov

Received 24 January 2020 Revised 12 June 2020 Accepted 17 June 2020

Check for updates

(c) Author(s) (or their employer(s)) 2020. No commercial re-use. See rights and permissions. Published by BMJ.

To cite: Kim SYH, Mangino D, Nicolini M. $J$ Med Ethics Epub ahead of print: [please include Day Month Year]. doi:10.1136/ medethics-2020-106091

\section{ABSTRACT}

In euthanasia and/or assisted suicide (EAS) of persons with dementia, the controversy has mostly focused on decisionally incapable persons with very advanced dementia for whom the procedure must be based on a written advance euthanasia directive. This focus on advance euthanasia directive-based EAS has been accompanied by scant attention to the issue of decision-making capacity assessment of persons with dementia who are being evaluated for concurrent request EAS. We build on a previous analysis of concurrent request EAS cases from the Netherlands, which showed that many such cases involve persons with significant cognitive impairment. We use illustrative cases to describe the difficulty of determining decisional capacity in persons whose stage of dementia falls between severely impaired and mildly impaired. We show that the Dutch practice of capacity assessment in such dementia cases is difficult to reconcile with the widely accepted functional model of capacity - a model explicitly endorsed by the Dutch euthanasia review committees. We discuss why such deviations from the standard functional model might be occurring, as well as their ethical implications for dementia EAS policy and practice.

Around the globe, a small number of countries permit euthanasia and/or (physician) assisted suicide (EAS) and the Benelux countries, and likely now also Canada after a recent court ruling, ${ }^{1}$ permit the practice whether or not the requestor's natural death is near. In the Netherlands, people, therefore, receive EAS for a wide range of non-terminal conditions, including for dementia, but these practices remain controversial. ${ }^{2-4}$ In EAS for dementia ('dementia EAS'), the controversy has mostly focused on EAS for decisionally incapable persons with advanced dementia for whom the procedure must be based on a written advance euthanasia directive (AED). ${ }^{35}$ For example, the only doctor who has ever been prosecuted after reporting a case of EAS to the Dutch euthanasia review committees (RTE) performed an AED-based EAS in a woman with advanced dementia. ${ }^{6}$

This predominant focus on the ethics of AEDbased EAS has been accompanied by surprisingly scant attention to an obvious ethical issue in dementia EAS based on concurrent requests. That is, since dementia is a well-established risk factor for incapacity in decisions regarding treatment, research participation, and preparation of advance directives, ${ }^{7-10}$ and given the serious nature of the decision to request EAS, how should someone's decisional capacity or competence ${ }^{i}$ be assessed? What criteria are relevant and how should they be applied (eg, what is the proper threshold)? What accounts for this lack of discussion of these questions?

We suspect that this relative silence has been due to the fact the cases of concurrent request dementia EAS have largely been presented as straightforward situations of early dementia in which persons have clear decisional capacity. Of the over 800 cases of dementia EAS performed in the Netherlands in the past decade, more than $98 \%$ have been deemed concurrent request cases (ie, not based on AED) according to the RTE. ${ }^{11}$ The RTE sees these as earlystage dementia cases: 'in nearly all the cases so far notified to the committees, the patient was in the early stages of dementia. ${ }^{11}$ The RTE states that at this stage 'the patient generally has sufficient understanding of his disease and is decisionally competent in relation to his request for euthanasia'. ${ }^{11}$ This explains why the RTE requires specialist input in capacity assessments for late-stage dementia but not generally for early stage cases. ${ }^{11}$ Thus, the reason why there has not been much discussion about capacity evaluations for concurrent request EAS in dementia seems to be, at least according to those reviewing the cases, that they involve straightforward capacity evaluations of persons in early stage of dementia.

A recent analysis of 59 concurrent request dementia EAS cases published by the RTE between 2011 and October 2018, however, found that concurrent request EAS can involve significantly impaired persons (eg, one in five requiring nursing home care) whose decisional capacity assessments are not straightforward. ${ }^{4}$ Indeed, one or more of the following elements were present in 31\% (18 of 59) of the concurrent request EAS cases ${ }^{4}$ : at least one physician viewed the patient as incompetent to request EAS; the physicians used the patients' prior stated (oral or written) statements as evidence for finding of competence; or the physicians inferred evidence for competence by interpreting patients' body language. In box 1 , we have selected four illustrative cases from among these for our discussion below. These cases exhibit the challenges that arise in dementia states that fall between early and (very) late stages.

${ }^{\mathrm{i}}$ As is common practice, we use 'competence' and 'capacity' interchangeably when referring to decision-making capacity. If needed, one can add 'adjudicated' when referring to a court determined status of decisional capacity/competence. 
Ms A was a woman in her 80 s who had unspecified dementia for 6 years and macular degeneration for 20 years at the time of her EAS. For years she had feared entering a nursing home and had previously talked about EAS. She received an 'early consultation' for EAS by a SCEN $\dagger$ consultant 11 months prior to death. The consultant found that Ms A's decisional capacity at that time was 'insufficient'. A month before death, Ms A made an official request for EAS and repeated it several times afterwards. 2.5 weeks before death, a geriatric specialist deemed her request 'voluntary and well considered'. 1.5 weeks prior to death another SCEN consultant agreed that all criteria were met. However, after the EAS, the euthanasia review committee (RTE) had questions about how this consultant arrived at her conclusions. In response, the SCEN consultant 'explained in writing that patient answered with 'ready is ready' when she had asked her whether she wanted to die. From the context it was clear to the consultant that this remark was a request to let her die. The consultant was convinced that patient knew that she had come to talk about dying. Patient probably did not know that the consultant was a SCEN physician. It was difficult to explain to her the notion of a SCEN physician due to the seriousness of her dementia. The consultant had decided that patient's request was voluntary and repeated, not so much because of the verbal expression of a euthanasia request, but because of her body language.' In determining Ms A's capacity, the consultant also relied on conversations with the patient's physician regarding the patient's previously stated wishes.

Mr B was a man in his 70s diagnosed with Mild Cognitive Impairment 5 years prior to EAS, then Alzheimer's disease 2 years later. Six months prior to death, his decline accelerated. Partly because of his past experience with a loved one dying from dementia, the patient had talked for years about EAS with his family physician who knew him well. A week prior to death, the patient asked his physician 'to actually implement the termination of life in the terms 'last bus ride' and 'end time.' According to the SCEN consultant, 'a real conversation with the patient was no longer possible and patient could no longer clearly state his euthanasia wish. In a way, the patient realised that it was about dying. Patient made an incomprehensible, deplorable, searching impression.' The patient was 'no longer competent' according to the consultant. However, the consultant stated that the due care criteria had still been met because 'the patient's situation fully corresponded with his euthanasia wish' expressed in previous statements and 'documented conversations with his family doctor and wife' and the consultant felt 'it is reasonable to assume' that the 'euthanasia wish of the patient has not changed.' When the RTE questioned the physician and the consultant regarding why a specialist had not been consulted, the physician said that the 'patient was not yet incapacitated. Life did not pass him by, he did not vegetate' and the consultant 'felt that the patient was still sufficiently aware of his situation.'

Ms C was in her 70s with a 5-year history of Alzheimer's disease and vascular dementia who had written an advance euthanasia directive (AED) 3 years prior to EAS which she confirmed a year later (and also had spoken about euthanasia with her primary care physician 'n the last 10 years before her death'). After two physicians declined to evaluate her for EAS, an End-of-Life Clinic physician took over the case. About a month before EAS, a SCEN consultant (a geriatric specialist) deemed her not capable; she later declined to evaluate the patient again when requested to do so because she felt 'another conversation with the patient about her euthanasia request seemed useless' but ultimately deemed all due care criteria were met as an advance directive-based EAS case. However, the EAS physician felt the patient was competent 'until the very end,' 'despite the fact that patient did not satisfy Appelbaum's criteria.' The physician relied not only on conversations with the patient but also on conversations with 'the people involved' as well as on the living will and the written statement of intent 'to become convinced that the due care requirements were met.' The EAS physician said the patient was clear in her request 'in her own way' in 'at least three of the four conversations.' The EAS physician explained that '(Ms C) sometimes just babbled, often out of frustration that she could not find the right words, but then she suddenly could say something. She indicated her wish to die in the three conversations the physician had with her, although indirectly and sometimes cryptically.' The physician reported that when Ms C was told she would receive EAS, 'she became calm....visibly happy,' and her 'eyes sparkled.' At implementation Ms C'seemed aware of what was about to happen' and even asked 'Can we now not continue?' during the procedure when they had difficulty finding a vein. The RTE commended the EAS MD for her careful management of the case, and accepted her opinions about Ms R being capable and further noted the EAS physician's opinion 'was confirmed by patient's statement of intent and living will.'

Mr D was a man in his 80 s who began having trouble with memory and aphasia 5 years prior to EAS, which progressed beginning 2 years prior to the point that he could not shop for himself and would get lost outside his own neighbourhood. Three months prior to EAS, there was 'acute deterioration' with 'agitation, anxiety, confusion and hallucinations at night' but during the day 'it was often possible to have a conversation' with him. He was then diagnosed with dementia by a psychiatrist; a neurologist suggested further workup but the primary care physician (the physician who performed EAS) felt treatable conditions had been excluded and 'thought it probable that the acute deterioration was due to cerebrovascular ischaemia, even though no indications were found for this on an MRI.' The physician reported that in the 3-month period prior to EAS, the patient had several lucid periods (twice in final week) during which he requested EAS. The SCEN consultant was a psychiatrist who saw the patient 6 weeks and 2 weeks prior to death. During the first visit, 'the patient was friendly and cooperative and answered all questions. However, it was unclear whether he understood the purpose of the consultant's visit. The subject of conversation was difficult to maintain. According to the consultant, the patient's competence was difficult to assess, and above all he did not express his opinion clearly.' During the second visit, the consultant 'determined that the patient recognised him, but could not indicate when he would like to see his life ended. In any case, according to the consultant, he did not seem to long for death to come soon.' Four days prior to EAS, the EAS MD called the consultant and told him that patient had had a lucid period during which 'he was without a doubt competent' and requested EAS 'within a few days' and the consultant then concluded due care criteria were met.

${ }^{*}$ For ease of reference in the text, we have given the cases fictitious names. The actual case numbers are: Ms A (case 2014-66), Mr B (case 2018-21), Ms C (case 2016-39), Mr D (case 2013-84). All four reports can be located at https://www.euthanasiecommissie.nl/uitspraken-en-uitleg by entering the case number in the search box. The reports contain more detail than presented here. We have distilled the cases by focusing on decisional capacity.

TSCEN refers to Support and Consultation on Euthanasia in the Netherlands. They are physicians specially trained to serve as EAS consultants. ${ }^{24}$

This paper focuses on this relatively neglected topic of challenges in capacity evaluations in persons with dementia being assessed for concurrent request EAS. Specifically, we use illustrative cases to point out the difficulty of determining decisional capacity in persons whose stage of dementia falls somewhere between severely impaired and mildly impaired. We show 
that some aspects of the practice of capacity assessment in these cases are difficult to reconcile with the widely accepted functional model of capacity - a model explicitly endorsed by the RTE. We then discuss why such deviations from the standard functional model might be occurring, as well as their ethical implications for dementia EAS policy and practice.

\section{IS THE FUNCTIONAL MODEL THE BASIS FOR DETERMINING CAPACITY IN COMPLEX CASES?}

The RTE's Code of Practice advises doctors involved in EAS to apply the following model of capacity:

\begin{abstract}
Decisional competence means that the patient is able to communicate intelligibly about his request for euthanasia and understand the relevant medical and other information. He must have insight into his condition: in other words he can assess his situation and the implications of euthanasia or alternative treatment. Finally, he must be able to make it clear why he wants euthanasia to be performed. ${ }^{11}$
\end{abstract}

The model here is obviously a functional model. It is a framework made familiar by the pioneering work of Appelbaum and Grisso $^{12}$; indeed, Dutch physicians and the RTE in their EAS reports sometimes refer to the 'Appelbaum criteria. ${ }^{13}$ Their four abilities model is quite similar to the one endorsed by the RTE: ability to communicate a choice ('communicate intelligibly about his request'), to understand the relevant information ('understand the relevant medical and other information'), to appreciate the situation and its consequences ('insight into his condition: in other words he can assess his situation and the implications of euthanasia or alternative treatment') and to reason ('make it clear why he wants euthanasia').

The cases summarised in box 1 are from published reports by the RTE, focusing on elements directly relevant to decisional capacity. According to the RTE, all four patients were considered competent and received euthanasia based on their own concurrent requests. What is surprising is that it is not obvious the assessments of their capacity were primarily based on a functional model of capacity. In fact, in the case of Ms C, the EAS performing doctor explicitly stated that she found her competent 'despite the fact' that the patient did not meet the 'Appelbaum criteria'.

In the case of Ms A (see box 1), she was found to have insufficient decisional capacity 11 months prior to EAS but 10 months later the SCEN consultant deemed her competent by inferring from the context that 'ready is ready' referred to EAS. She found Ms A competent 'not so much because of the verbal expression of a euthanasia request, but because of her body language' in conjunction with other contextual features. The description of Ms A's state at the time of the consultation (eg, not being able to understand what a SCEN consultant was) is not of someone who is able to demonstrate her understanding of relevant medical information or demonstrate her ability to assess her own situation, or weigh the pros and cons of her options.

Mr B's SCEN consultant found that he could no longer have a ' real conversation' nor 'clearly state his euthanasia wish' and thus found him 'no longer competent.' And yet, this consultant still found that all due care criteria had been met-with heavy reliance on her knowledge of Mr B's previously stated wishes. Mr B's case is not unique in this regard. In another case (2014$33)$, the consultant argued that 'the patient was not fully competent, but she certainly was with regard to her request.' Although this is a position theoretically compatible with decision-specific nature of functional capacity, what is unusual is the consultant's reasoning that the 'patient was not competent [at the time of evaluation] but she had been until recently. Her desire for euthanasia had been so consistent lately that the reduced competence should not be a stumbling block...' In Mr B's case, it is also telling that the EAS doctor said the 'patient was not yet incapacitated' by noting that 'he did not vegetate'-suggesting that this doctor's view is that one needs to have very advanced disease to lose decisional capacity.

In the case of Ms C, the consultant found her incompetent but unlike the consultant in Mr B's case this consultant did not equivocate or revise her view; she made it clear that she considered the case an advance directive-based EAS. This was a geriatric specialist who had earlier determined that the patient lacked capacity, and specifically stated that another evaluation would be useless. In a sense, the EAS doctor agreed with this opinion because she stated that the patient did not meet 'the Appelbaum criteria.' However, both the EAS physician and the RTE relied on their views about the patient's prior stated wishes to interpret the patient's current communications. Thus, Ms C's indirect and cryptic oral communication and her body language were taken as supporting evidence for an underlying desire for EAS, while her disruptive behaviours were seen as manifestations of a person frustrated by aphasia. As in other cases, the focus was deciphering the consistency of the request; it is not clear how the other functional abilities could have been assessed in this patient.

Mr D's case was complex in that the independent consultant, despite two evaluations (including a conversation in which the patient was able to 'answer all questions') could not confirm $\mathrm{Mr}$ D's capacity and indeed on the second visit felt the patient 'did not seem to long for death to come soon.' But this consultant then agreed with the requesting EAS doctor's telephone report that the patient had made a competent request for EAS to occur 'within a few days.' The content of the phone call from the EAS doctor to the consultant describing the evaluation is not given in any detail. One also wonders in what sense the consultant's opinion is an independent one, if it is pivotally dependent on the report of the requesting physician.

\section{THE COMPLICATED PRACTICE OF CAPACITY ASSESSMENT IN DEMENTIA EAS}

These are not straightforward capacity evaluations. Although the case reports cannot be relied on as comprehensive medical reports, the problem is not that these RTE reports do not fully capture the details of the capacity evaluations. There is positive evidence of difficulties. It is clear that some doctors (and the RTE) do not closely follow the functional model, and explicitly say that a person is competent even though the functional criteria are not met. The focus is primarily on the repetition of requests (ability to communicate a choice). But even when patients can state a choice, their abilities to understand, appreciate and reason about the choice are quite limited and these abilities must therefore be either ignored or presumed by the evaluators, as when the physicians (and the RTE) rely on the patient's prior stated views as evidence in support of her current functional capacity. ${ }^{\text {ii }}$ How are we to understand the process of determination of capacity in these cases?

\footnotetext{
${ }^{i i} A$ patient's previous statements, including an AED, can of course be useful in assessing a patient's competence without being relied upon as a basis for a judgment of competence. For example, Hertogh (2009) describes a woman suffering from early vascular dementia whose AED was used by evaluators to elicit
} 


\section{Functional model with a low threshold?}

One possibility is that the doctors and the RTE in their final judgements of the above cases are still using the functional model but with a very low threshold. After all, the functional model of capacity needs to be applied by clinicians with the threshold adjusted for the context. ${ }^{14-17}$ It may be that the doctors and the RTE feel that the decisional context requires only a very low capacity threshold. But if the practice is framed this way, what contextual factors justify the use of that low threshold? The threshold should in practice be set to conform to the dictum, as Lord Donaldson put it in re $T$, "What matters is that the doctors should consider whether at that time he had a capacity which was commensurate with the gravity of the decision which he purported to make. The more serious the decision, the greater the capacity required. ${ }^{18}$ This view is echoed in the guidance document endorsed by the $\operatorname{RTE}^{17}$ (p. 15) as well as by Grisso and Appelbaum when they state that 'it is consistent with most legal and ethical perspectives that judgments of competence... should consider the degree of potential benefit and potential harm to patients if their decisions are honoured. ${ }^{14}$ (p. 136) So the practice would make sense if providing EAS is analogous to providing a much needed beneficial treatment that has considerable benefit but little risk.

But there is no generally accepted view that providing EAS to persons with dementia is analogous to providing a treatment that is highly beneficial with low risk. We do not, for example, assume that most reasonable people would choose active termination of life in 'early stages' of dementia the way we assume that most people would choose an antibiotic to treat a serious infection. Accordingly, one does not find in the RTE's guidance to capacity evaluators that a low threshold for capacity should be used. Instead, the RTE states that '[i]n cases involving patients with dementia, there is also reason to exercise particular caution when considering whether the statutory due care criteria have been met. This is especially true of the criteria relating to decisional competence and unbearable suffering. ${ }^{11}$ Although the RTE here does not explicitly state that the threshold should be set high, it would be difficult to interpret this guidance as a justification of a low threshold based on widely accepted benefits and harms of EAS for a person with dementia.

\section{Prior statements and authenticity}

In the above cases, it is notable that the physicians and the RTE emphasise the patient's prior stated statements in favour of EAS as part of the capacity determination. Indeed, it seems this has such a powerful appeal that one consultant concluded that a patient was 'competent' even though she was not competent at the time of her evaluation: the patient's 'desire for euthanasia had been so consistent lately that the reduced competence should not be a stumbling block' (2014-33). But there is something amiss about using the patient's prior statements this way and calling it an application of a functional model of capacity. ${ }^{\text {iii }}$ If the evaluator's interpretation of the 'true' or 'authentic' wishes of the patient does the bulk of the work in determining the patient's current competence, then it seems odd to call that functional competence.

It is crucial to note we are not saying there is no moral weight to a person's prior stated wishes; in fact they might be quite

\footnotetext{
the patient's range of concurrently intact functional abilities.

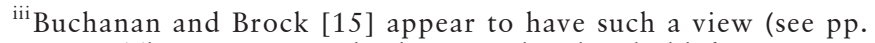
51-57). They recommend adjusting the threshold for capacity by taking into account the patient's 'underlying enduring aims and values.'
}

morally significant—for example, when the question at hand is making an optimal surrogate decision. The point is that the goal of assessing a person's functional capacity to make a decision is to determine whether the person in front of us now is the authoritative decision-maker. Some may believe that the right thing to do, all things considered, is to base our actions on the person's prior stated wishes; but we should not confuse that with saying the person here and now has sufficient functional capacity to be the decision-maker.

\section{Oral advance euthanasia statements?}

In the above cases, the threshold for capacity used seems so low that something akin to an assent (an affirmation) is taken as sufficient for a competent request. This observation raises the question: How does the practice of using a very low threshold for competence (justified by the knowledge of patient's prior stated desire for EAS) differ from implementing an oral advance request (assuming it is a case without a written AED) combined with a requirement for assent? Consider the following passage from the RTE's Code of Practice:

Even if the patient is no longer able to communicate normally, it may be possible to establish from his behaviour and utterances that his current wishes are consistent with wishes previously expressed, confirming the advance directive. ${ }^{11}$ (p. 45)

This is the RTE's guidance about how a written AED should be applied. But if 'the advance directive' in the text is dropped, it is striking how well the passage captures the actual procedures used in our concurrent request EAS cases above. ${ }^{\text {iv }}$ Thus, the complex and puzzling practices of capacity determination observed in the above cases become readily recognisable when seen as ways of carrying out an oral advance request (relying on prior statements and conversations) with the additional requirement that the person be able to provide assent. ${ }^{\mathrm{V}}$ However, the problem with understanding the current Dutch practice as implementing an oral advance directive as a basis for EAS is that such a practice is not legal when there is no written AED.

In summary, the practice of assessing capacity in these cases is difficult to reconcile with a strict application of the functional model of capacity. Understanding the practice in terms of a functional model would require a low threshold for capacity but no generally accepted justification for such a threshold exists. However, the practice as described aligns with what one might expect if oral advance requests were being carried out but such a practice is not legal in the Netherlands.

Some may dismiss our analysis on the grounds that the published RTE cases are exceptional and not representative, and therefore, ought not be the basis for any generalisations. In response, we note that what makes these cases special is the enormous complexity generated by the all too familiar problems associated with progression of dementia beyond the 'early' iv This passage resembles a passage in the Euthanasia Code
focusing on persons with isolated communication problems:
'the patient can still express his request orally, but is unable to
present supporting arguments... The utterances the patient is still
able to make at that point can be assessed in conjunction with
earlier oral or written directives, and the patient's behaviour
or signals.' (p. 18) This may make sense when the problem is an
isolated communication problem. But dementia is a dysfunction
in multiple cognitive domains.
'Note that Ms C had an AED. Given the controversial nature of
the practice, however, EAS performing doctors likely have an
incentive even in such cases to see the case as concurrent request
cases.

Kim SYH, et al. J Med Ethics 2020;0:1-5. doi:10.1136/medethics-2020-106091 
stages. As such, they are illustrative, not exceptional, cases. We doubt that all cases of dementia cases consist of mostly very mild dementia cases and extremely rare instances of AED-based cases, especially since there is a natural and powerful incentive for persons to wait beyond the very mild stages before seeking implementation of EAS.

\section{CONCLUSION}

The debate over EAS for persons with dementia has almost exclusively centred on the difficulties involved with EAS based on AEDs. ${ }^{3619-21}$ The result has been that important ethical issues in the practice of providing concurrent request EAS in persons with dementia has been neglected. In particular, the difficulty of determining the capacity of persons with dementia requesting EAS, especially when patients fall somewhere between severely impaired and mildly impaired, has received virtually no discussion in the field. This neglect is especially puzzling given that the research literature on capacity of persons with dementia consistently shows that persons even in early stages of dementia are very often-based on assessments using the widely accepted functional models of capacity-incompetent to consent to treatment, ${ }^{22}$ to research, ${ }^{10} 23$ or to write an advance treatment directive. $^{9}$

Our analysis provides an explanation for the relative lack of discussion on this topic. It appears that the RTE's tendency to associate concurrent request EAS with 'early-stage' cases where determination of competence is straightforward has given the impression that these are unproblematic cases: 'At this stage (ie, 'early stage') the patient generally has sufficient understanding of his disease and is decisionally competent in relation to his request for euthanasia'. ${ }^{11}$ What our analysis shows is that the RTE can endorse such a picture only because, despite its apparent endorsement of a functional model of capacity, they and the Dutch EAS physicians do not in fact use the conventionally understood functional model of capacity in their evaluation of persons for concurrent request EAS. The deviation appears to be an accommodation prompted by situations in which the parties evaluating the patient believe they know what the patient would have wanted but the patient's concurrent decisional capacity, as defined by usual functional criteria, is quite impaired. This seems a novel practice whose merits deserve further discussion and debate, for example, whether a person's prior statements should be relied on to determine that person's current capacity, and whether those prior statements (not specified in writing) should meet some evidentiary standard in order to serve that function. Regardless of one's views on the matter, such a debate would serve the important purpose of drawing attention to a neglected question: Is the boundary between advance request and concurrent request EAS in persons with dementia as obvious as it is assumed to be?

Twitter Scott YH Kim @scottbioethics

Acknowledgements We thank Frank Miller for helpful comments on the manuscript.

Funding Funded in part by the Intramural Research Program of the NIH (ZIA CL010539-04 (C).
Competing interests None declared.

Patient consent for publication Not required.

Provenance and peer review Not commissioned; externally peer reviewed.

Data availability statement Data are available in a public, open access repository.

ORCID iD

Scott YH Kim http://orcid.org/0000-0002-9444-4627

\section{REFERENCES}

1 Truchon v. Attorney General of Canada 2019 QCCS 3792.

2 Kim SYH, De Vries RG, Peteet JR. Euthanasia and assisted suicide of patients with psychiatric disorders in the Netherlands 2011 to 2014. JAMA Psychiatry 2016:73(4):362-8.

3 Miller DG, Dresser R, Kim SYH. Advance euthanasia directives: a controversial case and its ethical implications. J Med Ethics 2019;45(2):84-9.

4 Mangino DR, Nicolini ME, De Vries RG, et al. Euthanasia and assisted suicide of persons with dementia in the Netherlands. Am J Geriatr Psychiatry 2020;28(4):466-77.

5 van Steenbergen E, Ritzen G. Artsen: dementerenden kunnen te eenvoudig euthanasie krijgen. NRC, 2017. Available: https://www.nrc.nl/nieuws/2017/02/09/artsen-tegeneuthanaseren-van-dementen-op-basis-van-wilsverklaring-a1545325 [Accessed 19 Dec 2017].

6 Court of the Hague. Case number 09 / 837356-18. September 11, 2019. ECLI: NL: RBDHA: 2019: 9506. Available: https://uitspraken.rechtspraak.nl/inziendocument?id= ECLI:NL:RBDHA:2019:9506

7 Okonkwo 0, Griffith HR, Belue K, et al. Medical decision-making capacity in patients with mild cognitive impairment. Neurology 2007;69(15):1528-35.

8 Kim SY, Caine ED, Currier GW, et al. Assessing the competence of persons with Alzheimer's disease in providing informed consent for participation in research. Am J Psychiatry 2001;158(5):712-7

9 Fazel S, Hope T, Jacoby R. Dementia, intelligence, and the competence to complete advance directives. Lancet 1999;354(9172):48.

10 Jefferson AL, Lambe S, Moser DJ, et al. Decisional capacity for research participation in individuals with mild cognitive impairment. J Am Geriatr Soc 2008;56(7):1236-43.

11 Regional euthanasia review committees, euthanasia code 2018, 2018. Available: https://www.euthanasiecommissie.nl/de-toetsingscommissies/uitspraken/brochures/ brochures/euthanasiecode/2018/euthanasia-code-2018

12 Appelbaum PS. Clinical practice. assessment of patients' competence to consent to treatment. N Engl J Med 2007;357(18):1834-40.

13 Doernberg SN, Peteet JR, Kim SYH. Capacity evaluations of psychiatric patients requesting assisted death in the Netherlands. Psychosomatics 2016;57(6):556-65.

14 Grisso T, Appelbaum PS. Assessing Competence to Consent to Treatment: A quide for physicians and other health professionals. New York: Oxford University Press, 1998.

15 Buchanan AE, Brock DW. Deciding for others: the ethics of surrogate decision making. New York: Cambridge University Press, 1989.

$16 \mathrm{Kim}$ SYH. Evaluation of Capacity to Consent to Treatment and Research. New York: Oxford University Press, 2010.

17 Guide for Assessing Competence (for the care provider) [Handreiking voor de beoordeling van wilsbekwaamheid (voor de hulpverlener)], 2007. Available: https:// www.euthanasiecommissie.n//uitspraken/publicaties/ec-2018-links/ec-2018-links/ec2018-links/handreiking-beoodeling-wilsbekwaamheid [Accessed 6 Jan 2020].

18 Re T (adult: refusal of medical treatment) [1992] 4 All ER 649 at 662.

19 van Delden JJM. The unfeasibility of requests for euthanasia in advance directives. $J$ Med Ethics 2004;30(5):447-51.

20 Hertogh CMPM. The role of advance euthanasia directives as an aid to communication and shared decision-making in dementia. J Med Ethics 2009;35(2):100-3.

21 Asscher ECA, van de Vathorst S. First prosecution of a Dutch doctor since the euthanasia act of 2002: what does the verdict mean? J Med Ethics 2020;46(2):71-5.

22 Marson DC, Ingram KK, Cody HA, et al. Assessing the competency of patients with Alzheimer's disease under different legal standards. A prototype instrument. Arch Neurol 1995;52(10):949-54.

23 Warner J, McCarney R, Griffin M, et al. Participation in dementia research: rates and correlates of capacity to give informed consent. J Med Ethics 2008;34(3):167-70.

24 Jansen-van der Weide MC, Onwuteaka-Philipsen BD, van der Wal G. Quality of consultation and the project 'Support and Consultation on Euthanasia in the Netherlands' (SCEN). Health Policy 2007;80(1):97-106. 